\title{
CLINICAL MANIFESTATIONS AND NEURODEVELOPMENTAL OUTCOMES OF POST NATAL CMV INFECTION TRANSMITTED THROUGH BREAST MILK IN THE ELBW INFANTS
}

\author{
L. Mei ${ }^{1}$, M. Spinelli ${ }^{1}$, M.G. Capretti ${ }^{1}$, R. Alessandroni ${ }^{1}$, E. Tridapalli ${ }^{1}$, L. Corvaglia ${ }^{1}$, M. Zanetti ${ }^{2}$, M. \\ Lanari $^{1}$, G. Faldella ${ }^{1}$ \\ ${ }^{1}$ Neonatology and Neonatal Intensive Care Unit - S.Orsola-Malpighi Hospital - University of Bologna, ${ }^{2}$ ENT \\ Unit - S.Orsola-Malpighi Hospital - University of Bologna, Bologna, Italy
}

Background and aims: The aims of the present study were to evaluate the clinical expression and the longterm outcomes of CMV infection breast milk transmitted in ELBW infants (birth weight $<1000 \mathrm{~g}$ ).

Methods: We conducted a prospective, observational study of 60 ELBW infants and their 60 mothers. Fresh breast milk samples and infants' urine were tested for CMV by means of culture tests once a week until discharge. Breast milk was also tested for CMV DNA.

Neurodevelopmental assessment was conducted until the $30^{\text {th }}$ month of corrected age (Griffiths test 1996).

The infected infants underwent Magnetic Resonance Brain Imaging between 12 and 24 months of age and ABR (Auditory Brainstem Response) at 12 months. Four infants were tested for COR (Conditioning Orientative Reflex) at 2 years of age and 3 infants at both 2 and 6 years of age.

Results: Sixty mothers were evaluated. Thirty-six of these were CMV-seropositive.

CMV was found in breast-milk of 21/36 mothers (58\%) (virus culture and DNA) and in 8/36 (CMV DNA) (22\%). The infection was transmitted to 7 infants, 4 (57\%) of which showed clinical signs at the moment of CMV-infection (desaturations and neutropenia). The infection was self-limited.

None of the children had abnormal psychomotor development at the examination and sensorineural hearing loss.

Brain neuroimaging was normal in the infected infants.

Conclusions: The study suggests that postnatal CMV infection via CMV-positive fresh breast milk is selflimited and is not associated with impairment of hearing function, neurological outcomes and abnormal brain. 